\title{
A Review of the Evidence Germane to the Putative Protective Role of the Macular Carotenoids for Age-Related Macular Degeneration
}

\author{
Sarah Sabour-Pickett \\ Technological University Dublin \\ John Nolan \\ Waterford Institute of Technology \\ James Loughman \\ Technological University Dublin, james.loughman@tudublin.ie
}

See next page for additional authors

Follow this and additional works at: https://arrow.tudublin.ie/otpomart

Part of the Optometry Commons

\section{Recommended Citation}

Sabour-Pickett, S., Nolan, J.,Loughman, J., Beatty, S:A Review of the Evidence Germane to the Putative Protective Role of the Macular Carotenoids for Age-Related Macular Degeneration. Molecular Nutrition Food Research, Volume 56, Issue 2, February 2012, Pages: 270-286. doi:0.1002/mnfr.201100219

This Article is brought to you for free and open access by ARROW@TU Dublin. It has been accepted for inclusion in Articles by an authorized administrator of ARROW@TU Dublin. For more information, please contact arrow.admin@tudublin.ie, aisling.coyne@tudublin.ie, gerard.connolly@tudublin.ie.

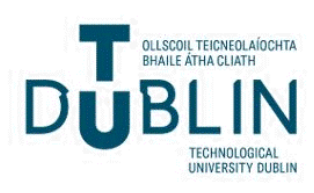


Authors

Sarah Sabour-Pickett, John Nolan, James Loughman, and Stephen Beatty

This article is available at ARROW@TU Dublin: https://arrow.tudublin.ie/otpomart/21 

protective role of the macular carotenoids for agerelated macular degeneration

${ }^{1}$ Department of Optometry, College of Sciences and Health, Dublin Institute of Technology, Dublin, Ireland

${ }^{2}$ Macular Pigment Research Group, Department of Chemical and Life Sciences, Waterford Institute of Technology, Waterford, Ireland

${ }^{3}$ Institute of Vision Research, Whitfield Clinic, Waterford, Ireland

${ }^{4}$ African Vision Research Institute, Faculty of Health Sciences, University of KwaZulu Natal, Durban, South Africa

Q1 There is a consensus that age-related macular degeneration (AMD) is the result of (photo)genetic background. The dietary carotenoids, lutein $(\mathrm{L})$, zeaxanthin $(\mathrm{Z})$, and meso-zeaxanthin (meso-Z), accumulate at the macula, where they are collectively known as macular pigment (MP). The anatomic (central retinal), biochemical (anti-oxidant) and optical (short-wavelength-filtering) properties of this pigment have generated interest in the biologically plausible rationale that MP may confer protection against AMD. Level 1 evidence has shown that dietary supplementation with broad-spectrum anti-oxidants results in risk reduction for AMD progression. Studies have demonstrated that MP rises in response to supplementation with the macular carotenoids, although level 1 evidence that such supplementation results in risk reduction of AMD and/or its progression is still lacking. Although appropriately weighted attention should be accorded to higher levels of evidence, the totality of available data should be appraised in an attempt to inform professional practice. In this context, the literature demonstrates that supplementation with the macular carotenoids is probably the best means of fortifying the anti-oxidant defenses of the macula, thus putatively reducing the risk of AMD and/or its progression.

\section{Keywords:}

Age-related macular degeneration / Lutein / Macular pigment / Meso-zeaxanthin / Zeaxanthin

\section{Introduction}

Q2 The macula is a specialised area of the retina, responsible for high acuity central vision and the perception of colour [1].

Correspondence: Sarah Sabour-Pickett, The Institute of Vision Research, Suite 14, Whitfield Clinic, Cork Rd, Waterford, Ireland E-mail: sarah.sabourpickett@gmail.com

Fax: $+353-319849$

Abbreviations: AMD, age-related macular degeneration; AREDS, Age-related Eye Disease Study; MP, macular pigment; PUFA, polyunsaturated fatty acid; ROI, reactive oxygen intermediate; RCT, randomised control trial; ROI, reactive oxygen intermediate; $\mathbf{R P E}$, retinal pigment epithelium
Age-related macular degeneration (AMD) is a degenerative condition of the macula, and its late form (i.e. visually consequential AMD, or VC AMD) is the leading cause of blindness in the developed world [2-5]. The prevalence of AMD will rise due to increasing life expectancy and the demographic shift towards an elderly population [6, 7]. VC AMD has a significant adverse impact on daily living, independence, emotional well being and overall quality of life, which are related to disease severity [8-10], not to mention the substantial personal and societal burden that this condition represents $[11,12]$.

The aetiology of AMD is poorly understood, yet there is consensus that genetic background and certain environmental/lifestyle risk factors, and their interaction, predis- 
pose an individual to the condition [13, 14]. Current treatment interventions, such as anti-vascular endothelial growth factor (anti-VEGF) agents, have resulted in better outcomes for patients with neovascular AMD [15-17]. Yet these are costly and cumbersome to the healthcare provider and to the patient. In addition, there is no effective treatment for atrophic AMD, which has a similarly detrimental effect on a patient's quality of life.

Two dietary carotenoids, lutein (L) and zeaxanthin (Z), and a typically non-dietary carotenoid, meso-zeaxanthin (meso-Z), accumulate at the macula where they are collectively known as macular pigment (MP) and give the macula its yellow appearance. $\mathrm{L}$ and $\mathrm{Z}$ can be obtained from many foods [18], whereas meso- $Z$ is not present in a conventional western diet, although it can be found in certain types of seafood [19]. A biochemical study on monkey retinas found that meso- $\mathrm{Z}$ is generated from $\mathrm{L}$ in the primate retina [20]. Z (including meso-Z) is the predominant carotenoid in the foveal (central) region, whereas L predominates in the parafoveal (paracentral) region. Interestingly, meso- $Z$ is found only in the epicentre of the macula [21].

MP has generated interest in the recent years because of its possible protective role in AMD, putatively attributable to its anti-oxidant properties and/or its pre-receptoral filtration of damaging (short-wavelength) blue light [22, 23]. There is a clear need for attention to be directed towards the prevention of AMD and its progression.

\section{AMD aetiopathogenesis}

\subsection{Oxidative stress}

As AMD is an age-related condition, the free radical theory of ageing is believed to be relevant to its aetiopathogenesis. This theory proposes that age-related disorders are the result of cumulative tissue damage following interaction with reactive oxygen intermediates (ROIs) [24, 25]. ROIs, which include free radicals, hydrogen peroxide and singlet oxygen, are unstable byproducts of oxygen metabolism. Free radicals, for example, lack (or possess an additional) electron in their outer orbit, and therefore seek to be neutralized by obtaining or transferring, respectively, an electron; a readily available source of electrons includes the double bond of a polyunsaturated fatty acid (PUFA). Thus, ROIs readily react with tissue macromolecules, resulting in impaired cell function and cell death [26]. The body's natural defence against ROIs includes their neutralisation by enzymes and/ or anti-oxidants [27]. However, generation of ROIs increases in response to environmental stresses, such as atmospheric pollution, asbestos exposure, tobacco use, irradiation and alcohol consumption [28, 29]. Oxidative injury occurs, therefore, when the level of oxidants (ROIs) in a system exceeds the detoxifying capacity of its anti-oxidant defence system [30].
The retina is made up of two layers, the photoreceptorand axon-containing neurosensory retina, and the underlying single-layer retinal pigment epithelium (RPE). The function of the RPE is to nurture, and remove waste products from, the neurosensory retina [31, 32]. AMD is characterised by loss of photoreceptors and by RPE cell dysfunction [33], the latter being largely attributable to an age-related accumulation of lipofuscin (yellow-brown pigment granules representing lipid-containing residues of lysosomal digestion) [34]. Of note, the accumulation of lipofuscin within the RPE cells increases as a result of incomplete digestion of oxidatively damaged photoreceptor outer segment membranes [35]. In turn, this yellow age pigment then acts as a photosensitiser (a compound which, when irradiated with light of an appropriate wavelength, emits an electron, thereby generating an ROI) [23, 36], thus provoking further oxidative injury [35, 37].

The retina is an ideal tissue for the production of ROIs, because of its high oxygen demand and consumption, exposure to visible light, metabolic activities (such as RPE phagocytosis) and the presence of photosensitisers (chromophores) [38]. In addition, the photoreceptor outer segments contain a high concentration of PUFAs, which are readily oxidised by ROIs, thus generating a cytotoxic chain reaction of events, thereby producing yet more ROIs and further and consequential oxidative injury [23, 28].

Light of shorter wavelengths (blue, ultraviolet (UV)) has greater energy than that of longer wavelengths (e.g. red, yellow) and is, therefore, more injurious to retinal tissue [39]. In the human eye, the cornea and crystalline lens efficiently filter most of the ultraviolet light [40]. However, substantial amounts of damaging, high energy, shortwavelength, blue (visible) light is incident upon the retina, even in an ambient setting [41].

Damage to the RPE and to the photoreceptors by visible light was first demonstrated in 1965 [42]. Later, it was shown that the blue part of the visible spectrum is most injurious [43]. Of note, it has also been demonstrated that such blue light (photo)-oxidative retinal damage is greater in the presence of high oxygen tension [44]. Lipofuscin also appears to play a decisive role in photo-oxidative stress in the retina, inducing the production of ROIs when irradiated with blue light as this pigment acts as a chromophore [45]. Indeed, and consistent with this, it has been shown that lipofuscin in RPE cells stimulates cell apoptosis when exposed to visible light [46, 47].

There is a growing consensus that cumulative lifetime exposure to visible light increases the risk of AMD [22, 48], consistent with the aforementioned findings. Furthermore, AMD-like lesions have been demonstrated in laboratory rats reared in ambient levels of light, when compared with rats reared in the dark [49]. Subsequent investigators have demonstrated that the generation of AMD-like lesions in monkey retinas, following exposure to light of varying wavelengths, requires 70-1000 times less power when using blue light compared with infrared wavelengths [50]. And 
finally, administration of anti-oxidants to laboratory rats exposed to continuous illumination has been shown to confer protection against photoreceptor loss [51]. In other words, there is a compelling body of evidence that cumulative exposure to visible (blue) light is an important contributor to the development of AMD and that the mechanism of its contribution rests on the (photo)-oxidative injury that such short wavelengths of visible light inflict upon the retina.

Of interest, ROI production (and, therefore, oxidative injury) peaks at the macula [52, 53], where AMD manifests.

\subsection{Inflammation}

There is a consensus that inflammation also plays a role in the pathogenesis of AMD [54, 55]. Inflammation is part of the complex, biological, non-specific, immune response of vascular tissue to harmful stimuli, such as pathogens, damaged cells or irritants [56]. It is believed that inflammation within the retina is a precursor to the formation of drusen (yellow waste deposits in Bruch's membrane under the retina) and the alteration of the extracellular matrix [57, 58]. These changes alter the RPE-choriocappillaris relationship, ultimately causing choroidal neovascularisation and other manifestations of advanced AMD [55, 59]. Of note, drusen have been shown to contain proteins associated with immune-mediated response and inflammation [59, 60]. Indeed, histological studies have consistently demonstrated the presence of chronic inflammatory cells in retinas afflicted with AMD [61, 62]. It is believed that these inflammatory cells damage tissue by releasing proteolytic enzymes and oxidants, thus compounding oxidative stress.

The inflammatory hypothesis of AMD has generated a lot of interest, especially given the discovery that subjects with a certain gene variant, one which is closely connected to the mediation of inflammatory processes, are significantly more at risk of developing AMD [63, 64].

Hollyfield et al. have eloquently shown that oxidative damage-induced inflammation is the initiator of AMD. The investigators demonstrated AMD-like lesions in mice immunized with mouse-serum albumin adducted with carboxyethylpyrrole, a unique oxidation product of docosahexaenoic acid known to adduct proteins in drusen from AMD donor eyes. Thusly immunized mice develop antibodies to this hapten, fix complement component-3 in Bruch's membrane (the site of drusen formation), accumulate drusen below the RPE during ageing, and develop atrophic changes within the RPE. In other words, it appears that oxidative damage represents the trigger for the development of AMD, the pathogenesis of which is mediated by the inflammatory response to that insult which in turn will be determined by genetic background. It follows, therefore, that prevention or attenuation of the initial oxidative injury will reduce the risk of developing $\mathrm{AMD}$, regardless of genetic background [65].

\section{$3 \quad$ AMD risk factors}

The three undisputed risk factors for AMD are: increasing age, positive family history of the disease and tobacco use [66-70]. Of note, the genetic predisposition to AMD is subject to environmental provocation [13, 14, 71]. However, there is a growing body of evidence that cumulative exposure to visible light in association with a lack of dietary intake of key anti-oxidants also represents an increased risk of AMD [72]. Interestingly, the three established risk factors for AMD (age, genetic background and tobacco use) are associated with a relative lack of MP before disease onset [73]. Moreover, a recent study has identified that age and tobacco use are also associated with an atypical, and most likely undesirable, central dip in the spatial profile of MP [74].

\section{$4 \quad$ MP}

\subsection{The origins of MP}

The macula lutea (yellow spot) was first identified more than two centuries ago. In 1792, Buzzi first described it in the human eye [75], and later in 1795 Soemmering independently discovered the foramine centrali limbo luteo (the central yellow-edged hole) [76]. The first review on "macular yellow" was published by Home in 1798 [77], which began an era of investigation into the composition, and function, of what has become known as MP [78], a term first coined in 1933 by Walls et al. [79]. The hypothesis that this pigment provides protection against the damaging effects of short-wavelength visible light was first proposed by Max Shultze in 1866 [80], and its function was further discussed in a series of studies in the early 20th century [79, 81-83].

In 1945, Wald demonstrated the spectral sensitivity of MP (using a spectral adaptometer), indicating that it had a characteristic carotenoid absorption spectrum and belonged to a family of xanthophylls found in green leaves [84]. However, it was not until as recent as 1985 that Bone and Landrum first proposed that the pigment was composed of the carotenoids, L and Z [85], and this was later confirmed in 1988 by Handleman et al. [86]. Meso-Z was later identified as being the third carotenoid present in the central retina, where it is the dominant carotenoid at the epicentre of the macula [87]. Bone et al proposed that meso- $Z$ was primarily formed at the macula following conversion from retinal $\mathrm{L}$ [21], and this has subsequently been confirmed $[20,88,89]$.

\section{The functions of MP}

The putative protective role of MP for AMD rests on at least one of the two following properties of this pigment. First, its

(a)

9

31

3

35

77

9

1

3


absorbance spectrum (peak absorption of this pigment is $460 \mathrm{~nm})$. Second, the ability of the macular carotenoids to quench ROIs, referred to as anti-oxidant capacity.

\subsection{Short-wavelength light filtration}

Although almost all UV-B (320-290 nm) and UV-A $(320-400 \mathrm{~nm})$ light is absorbed by the cornea and lens, light of slightly longer wavelength $(400-520 \mathrm{~nm})$ passes through the anterior media, and irradiates the macula [90]. Given that the peak absorption of MP is at $460 \mathrm{~nm}$ [84], it has the ideal light filtration properties to screen short-wavelength light pre-receptorally. This allows MP to attenuate the amount of blue light incident upon the central retina.

$\mathrm{L}$ is reported to be a superior filter of blue light when compared with $\mathrm{Z}$, due to its orientation with respect to the plane of the phospholipid bilayer of the cell membrane [91], which is both parallel and perpendicular. In contrast, $\mathrm{Z}$ and meso-Z only exhibit perpendicular orientation to this layer. However, it is important to note that the different absorption spectra of these pigments (L, $\mathrm{Z}$ and meso-Z) result in a collective optimal filtration of blue light at the macula, which would not be achieved by any of these carotenoids in isolation [91-93].

A recent analysis by the European Eye Study $(n=4753)$ found a significant correlation between cumulative exposure to visible light and neovascular AMD in those patients with low intake of dietary anti-oxidants, including L and Z [94]. A further study has recently reported the effect of low-power laser light $(476 \mathrm{~nm}$ (blue)) on the retinae of 8 rhesus monkeys who had lifelong deprivation of the dietary xanthophylls, and therefore no detectable MP. A further four monkeys (controls) had a typical dietary intake of $\mathrm{L}$ and $\mathrm{Z}$ from birth. The retinae of primates deprived of dietary xanthophylls until exposed to the low-power laser light, but then supplemented with either L or Z, were then exposed once again to the same laser light six months later. The relationship between lesion size and exposure energy was then analysed. The controls (primates with typical dietary intake of $\mathrm{L}$ and $\mathrm{Z}$ from birth) exhibited less severe blue-light induced lesions in the foveal region of the retina when compared to the parafoveal region (where there is no MP), whereas those with lifetime deprivation of xanthophylls and no measurable MP exhibited no difference between the fovea and parafovea in terms of blue light-induced retinal damage prior to supplementation, thus supporting the hypothesis that foveal photoprotection is indeed attributable to MP. This was further confirmed when, following either L or Z supplementation, relative foveal protection was restored, and these animals with prior lifelong deprivation of dietary xanthophylls no longer exhibited greater relative vulnerability of the fovea when compared with the parafovea, and were therefore similar to the control group in this respect following supplementation. In other words, and in spite of long-term carotenoid deprivation, supplemental macular carotenoids, whether L or Z, afforded the fovea protection from blue light injury [95].

\subsection{Anti-oxidant properties}

$\mathrm{L}, \mathrm{Z}$ and meso- $\mathrm{Z}$ are structural isomers of one another and are characterized, biochemically, by their high number of double bonds [21]. Their supply of readily available electrons enables these carotenoids to quench ROIs, thus limiting membrane phosopholipid peroxidation and attenuating oxidative injury [91, 96, 97]. Kirschfeld was the first to propose the idea that carotenoids protect the macula against oxidative stress [98]. However, it was not until 1997 that Khachik et al. confirmed the presence of direct oxidation products of $\mathrm{L}$ and $\mathrm{Z}$ in human retinal tissue, supporting the hypothesis that MP does indeed protect against oxidative damage in this tissue [99].

The anti-oxidant capacity of Z (and other carotenoids), however, has been shown to decrease with increasing oxygen tensions in the tissue [100]. Of note, MP is at its highest concentration in the receptor axon layer of the foveola and in the inner plexiform layer [101, 102]. Also, the concentration of the carotenoids within each retinal layer peaks at the foveola. Importantly, it is at this central retinal location where ROI production is greatest [103].

In vitro studies of human RPE cells, subjected to oxidative stress, have shown enhanced survival of these cells in the presence of $\mathrm{Z}$ and other anti-oxidants, when compared with controls [104]. Furthermore, L and Z are also more resistant to degradation than other carotenoids when subjected to oxidative stress [105]. Z appears to be a more potent anti-oxidant than $\mathrm{L}$ [106] and meso-Z is yet more efficacious, but only in conjunction with its binding protein [107]. Another study has demonstrated that light-induced photoreceptor apoptosis is limited in response to supplemental $\mathrm{Z}$ in quail (the retinae of which, like those of primates, selectively accumulate L and Z) [108]. Chucair et al. provided the first evidence of direct neuroprotection of photoreceptors by the macular carotenoids [109], by demonstrating that the retinal neurons of rats in culture were protected from oxidative stress when pre-treated with $\mathrm{L}$ and Z, compared with those not pre-treated with these carotenoids. Recently, Li et al. demonstrated that a mixture of $\mathrm{L}, \mathrm{Z}$ and meso- $\mathrm{Z}$ (in a ratio of 1:1:1) quenches more singlet oxygen than any of these carotenoids individually but at the same total concentration [110].

\section{The source of the macular carotenoids}

An average western diet contains $1.3-3 \mathrm{mg}$ /day of $\mathrm{L}$ and $\mathrm{Z}$ combined [111], with significantly more L than Z (represented by an estimated ratio of circa 7:1). It has been reported that approximately $78 \%$ of dietary $\mathrm{L}$ and $\mathrm{Z}$ is sourced from vegetables, with $\mathrm{L}$ found in highest concen- 
trations in dark green leafy vegetables (including spinach, broccoli, kale and collard greens) [18]. However, as most current dietary databases report intakes of $\mathrm{L}$ and $\mathrm{Z}$ combined, it has been difficult to assess the respective and relative intakes of the individual macular carotenoids. Recently, however, a study by Perry et al. did report concentrations of $\mathrm{L}$ and $\mathrm{Z}$ separately within the major food sources, as determined by the National Health and Nutrition Examination Survey (NHANES). In their study, they confirmed that green leafy vegetables were the richest source of L (e.g. cooked spinach and kale), whereas corn and corn products were confirmed as being a major source of $\mathrm{Z}$ [112]. Eggs are also a good source of L and Z, especially given the enhanced bioavailability of these carotenoids in this form because of co-ingestion of fat [113].

It appears that humans ingest relatively low concentrations of meso-Z (if any); however, research is ongoing in this area, given the recent interest in this centrally located macular carotenoid. To date, there has been no exhaustive assessment of the amounts of meso- $Z$ in a normal diet. However, eggs from hens fed meso-Z are known to be a rich human dietary source of this carotenoid [114]. Also, a study by Maoka et al. in 1986 reported that meso-Z and Z are present in 21 species of edible fish, shrimp, and sea turtles [19]. The presence of meso- $Z$ in the serum of unsupplemented individuals has never been unambiguously demonstrated, although efforts to extract and quantify meso$\mathrm{Z}$ in human blood have demonstrated that, if it is present, the concentrations of this carotenoid are low [115]. Interestingly, and in spite of its absence or low concentration in a normal diet, meso-Z accounts for about one-third of the total MP at the macula, consistent with the finding that retinal meso- $\mathrm{Z}$ is produced primarily by isomerisation of retinal $\mathrm{L}$ at the macula [20, 21].

\section{Types of evidence}

There is the notable challenge of fitting carotenoid research into the, sometimes rigid, paradigm of evidence-based medicine. Harbour and Miller [116] summarised the widely accepted hierarchy of study types adopted by the Agency for Health Care Policy and Research:

(i) Systematic reviews and meta-analyses of randomised control trials (RCTs)

(ii) RCTs

(iii) Non-randomised intervention studies

(iv) Observational studies

(v) Non-experimental studies

(vi) Expert opinion

A systematic review is a thorough, comprehensive and explicit means by which to identify, critically appraise and evaluate medical literature related to a specific research question. A meta-analysis is a statistical approach to combine and analyse the data derived from a systematicreview. RCTs are studies in which participants are allocated at random, rather than by conscious decision of clinician or patient (which is the case in non-randomised trials), to receive one of several clinical interventions, one of which typically acts as a control (placebo). The greater the sample size, the reduced likelihood of bias. In contrast, an observational study is one in which conclusions are drawn by observation alone, examples of which may include casecontrol and cohort studies.

Evidence quality is typically graded on the basis of study design, where systematic reviews or meta-analyses of RCTs are widely accepted as providing the best evidence (level 1) on the effects of preventative, as well as other, interventions in medicine [117]. (see Table 1)

Randomised controlled trials are regarded as the "gold standard" in clinical research, yet they have certain limitations [118] such as inappropriate outcome measures and/or biased sample recruitment. Given that studies involving humans are laden with ethical issues and, in many cases, may not be feasible, practical or indeed appropriate [118, 119], many important epidemiologic findings have been the result of observational studies. The weight accorded to RCTs can, in some instances, result in the exclusion of evidence arising from other and valid study designs. In other words, studies with alternative designs should be seen as complimentary, rather than an alternative, to RCTs.

AMD is a slow, complex disorder and the carotenoids under review, particularly L and Z, are already commonly found in the daily diet and are easily available in supplement form on the open market. This makes the conduct of "gold standard" randomized clinical trials particularly difficult. What is important to acknowledge is that all study designs contribute to an ever-growing body of knowedge in a given area. This point has been eloquently made by Hennekens [120]: "Every research strategy within a discipline, contributes importantly relevant and complimentary information

Table 1. Levels of evidence for therapy or prevention

Level Type of study

1a Systematic review (homogeneous) of RCTs

1b Individual RCT (with narrow confidence interval)

2a Systematic review of (homogeneous) cohort studies

2b Individual cohort study/low-quality RCT

3a Systematic review of (homogeneous) case-control studies

3b Individual case-control studies

4 Case series, low-quality cohort or case-control studies

5 Expert opinions without explicit critical appraisal, or based on physiology, bench research or "first principles"

Material adapted from the recommendations for evidence-based medicine in Oxford. http://www.cebm.net/index.aspx?o = 1025. 
to a totality of evidence upon which rational clinical decision making and public policy can be reliably based. In this context, observational evidence has provided and will continue to make unique and important contributions to this totality of evidence upon which to support a judgment of proof beyond a reasonable doubt in the evaluation of interventions."

While recognising the importance of study design in public health research, we are encouraged to give adequte attention to the completeness and transferability of evidence when interpreting the results of such studies. This has been eloquently articulated by Rychetnik et al, as follows: "Care is needed that the use of evidence hierarchies to compare the potential for bias between study designs does not translate into unrealistic or overly expensive demands for level 1 or 2 evidence, particularly if there is a good or adequete level 3 evidence to inform a decision" [121].

The reader should also be aware that the capacity and resources of competing stakeholders (e.g. pharmaceutical companies, academic institutions, among others) to generate and disseminate evidence has a profound influence on the prestige and volume of available and published literature on a given subject [121].

\section{AMD and the macular carotenoids: The evidence (Table 2)}

\subsection{Randomised control trials}

\subsubsection{Proof of principle}

In 2001, the Age-related Eye Disease Study (AREDS) was published, having been conducted by the National Eye Institute (NEI). This was a double-masked, randomised, placebo-controlled trial of 4757 subjects over a period of 5 years. In brief, it was shown that supplementation with vitamins $\mathrm{C}$ and $\mathrm{E}, \beta$-carotene, and zinc in combination resulted in a $25 \%$ risk reduction of progression from intermediate to advanced AMD. Of note, the AREDS did not supplement with any of the macular carotenoids, primarily because these compounds were not available in supplement form at the inception of that study. This important study did, however, provide level 1 evidence that demonstrates that supplemental dietary anti-oxidants were beneficial for patients with AMD.

\subsubsection{AMD and the macular carotenoids}

There are now many published interventional studies reporting on AMD and the macular carotenoids (Table 2) [122-126].

In 2004, the LAST study (Lutein Antioxidant Supplementation Trial) was carried out in an attempt to evaluate the effect of L, either alone or in combination with addi- tional carotenoids, anti-oxidants, vitamins and minerals on the progression of atrophic AMD [125]. This study was a prospective, 12-month, randomised, double-masked, placebo-controlled trial, involving 90 subjects with atrophic AMD. The subjects were assigned to one of three groups: group 1 received L only $(10 \mathrm{mg})$; group 2 received a broadspectrum supplementation formula containing L (10 mg) as well as anti-oxidants, vitamins and minerals; group 3 received a placebo. Results showed that the subjects in Groups 1 and 2 demonstrated an increase in mean MP optical density as well as an improvement in visual acuity, contrast sensitivity, glare recovery and visual distortion. This study, therefore, demonstrated that visual function is improved in patients with atrophic AMD following supplementation with either $\mathrm{L}$ alone or $\mathrm{L}$ in combination with antioxidants, vitamins and minerals. However, the LAST study is open to legitimate criticism on the basis of the small number of patients recruited into each arm of the investigation, and the short follow-up (ie. only 12 months).

The Carotenoids in Age-related Maculopathy (CARMA) study was a randomised, double blind, placebo-controlled clinical trial of $\mathrm{L}(12 \mathrm{mg})$ and $\mathrm{Z}(0.6 \mathrm{mg})$ supplementation with co-anti-oxidants versus placebo in patients with AMD [127]. This study included 433 subjects, who were recruited and randomly assigned to the treatment or the placebo arms of the study. Although the primary outcome measure (best corrected visual acuity (BCVA) at one year) did not differ between the placebo and the intervention arms of the study, it was noted that corrected distance visual acuity was significantly better in the intervention arm of the study at 36 months follow-up. In addition, an increase in serum $\mathrm{L}$ was associated with significantly improved BCVA and slowing of progression along the AMD severity scale [126]. It is important, however, to note there are several limitations in the CARMA study design, despite it being an RCT. These limitations include a relatively small sample size, particularly at 36 months $(n=41,20$ in the intervention group and 21 in the placebo group), and the questionable appropriateness of its primary outcome measure (BCVA at 12 months), given the chronic nature of AMD.

Moreover, the other studies presented in Table 2, although RCTs, have several limitations in their respective study designs, including small sample sizes, stated outcome measures, and lengths of follow up.

\subsubsection{Trials awaiting completion}

There are a number of trials underway investigating the putative protective role of $\mathrm{L}$ and $\mathrm{Z}$ in individuals with AMD. The AREDS 2 is an ongoing multi-centre RCT ( $n=4000$ approximately) designed to evaluate the effect of supplemental L and Z (and/or $\boldsymbol{\omega}$-3) with respect to the progression to advanced AMD. Additionally, it seeks to assess whether modified forms of the original AREDS supplement, with reduced zinc and/or no $\beta$-carotene, work as effectively as the 


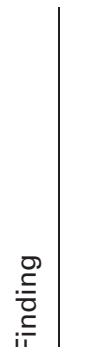

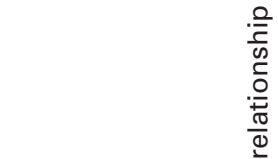

$\sum \stackrel{0}{\infty}$

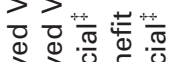

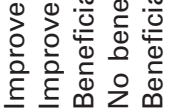

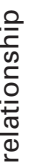

15

कิ के के के है

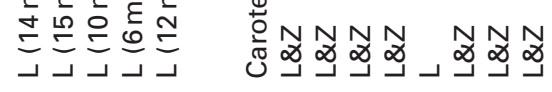

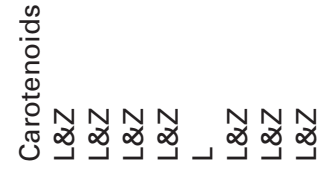

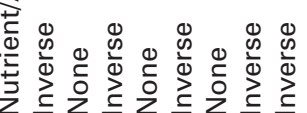

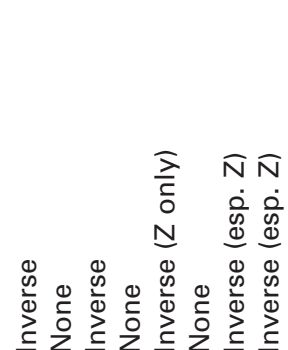

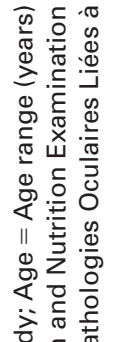

西

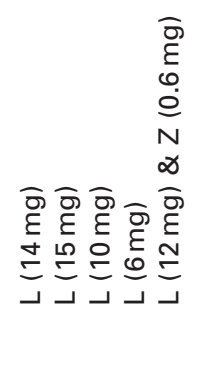

(1)

m.1.1.

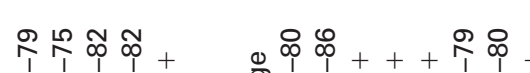

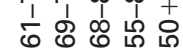

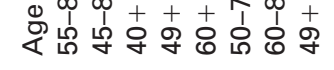

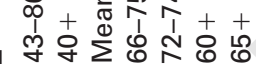

ติ

Wै

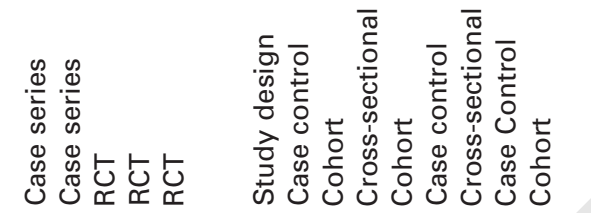

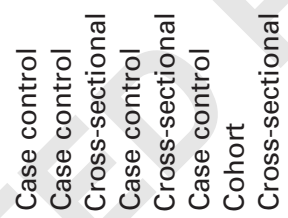

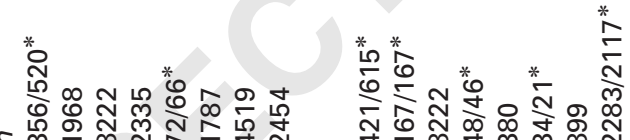
丬 
original supplement in reducing the risk of progression to advanced AMD.

The study is expected to be completed in December 2012 (http://clinicaltrials.gov/ct2/show/NCT00345176?term = AREDS2\&rank =1). The results of AREDS 2 will provide invaluable and timely data on the potential role of antioxidants, including $\mathrm{L}$ and $\mathrm{Z}$, in delaying AMD progression, and will inform current professional practice with respect to the role of dietary modification and/or supplementation in patients with AMD. A limitation of the trial, however, rests on the fact that MP is not being measured. Therefore, a finding that supplemental $\mathrm{L}$ and $\mathrm{Z}$ in AREDS 2 is not beneficial cannot be interpreted to mean that MP augmentation is not beneficial, as the latter will not have been demonstrated.

Results from recent studies, as yet unpublished, have demonstrated visual improvement in response to macular carotenoid supplementation, and this improvement correlated with the observed increase in MP in eyes afflicted with AMD [128, 129].

\subsection{Future considerations}

There have been no published trials investigating the potential of dietary carotenoids in terms of prevention of AMD, which would involve recruiting subjects who are not afflicted with the condition and evaluating the incidence of AMD with respect to dietary intake of the dietary carotenoids and with respect to MP optical density. The trial would be observational in design rather than interventional, as the study period would need to be not less than 15 years in duration following completion of recruitment. Of note, however, a study of such unique design is currently underway in Ireland. The Irish Longitudinal Study of Ageing (TILDA) [130], is investigating health, lifestyles and financial status of circa 8000 randomly selected people aged 50 years and older. A major component of this prospective cohort study is the investigation into the relationship between baseline MP levels and the prevalence and incidence of AMD [131]. MP measurements and retinal photographs are being obtained at three separate study waves: year 1 (started December 2009, and is now near completion), year 4 and year 8 . This study will investigate, for the first time, whether baseline MP levels relate to the ultimate risk of developing AMD.

Furthermore, no trials to date have investigated the potential of meso-Z with respect to development or progression of AMD, as it has only recently become available in supplement form. Of note, meso-Z, which accounts for one third of total MP [21], and of the three macular carotenoids, is the most powerful anti-oxidant [107]. Emerging evidence has also shown that the central dip in MP, an anatomic characteristic associated with the undisputed risk factors for AMD (ageing and tobacco use) [74], is negated by a meso-Z dominant supplement [115].

\subsection{Observational studies}

A large number of studies have investigated the relationship between dietary intake of the macular carotenoids and AMD (Table 2) [72, 132-138]. Of these eight published observational studies, five reported a negative association between high dietary intake of the carotenoids and AMD. Serum carotenoid levels and their relationship with AMD risk have also been assessed [94, 134, 139-144]. Of the eight studies published, five have demonstrated an inverse association between serum concentration of the macular carotenoids and risk for AMD.

\subsection{Dietary, serum, and retinal response to supplementation with the macular carotenoids}

There have been many published studies on serum and retinal response (i.e. MP optical density) to supplementation with the macular carotenoids (Tables 3 and 4, respectively), in normal and in AMD subjects.

Of the published studies commenting on serum carotenoid response following supplementation with macular carotenoids, a mean $( \pm \mathrm{sd})$ L concentration increase of 330 ( \pm 342 )\% (range: 16 to $1500 \%$ ) within 19 (range: 3 to 48 ) weeks was observed. Similarly, a mean $( \pm \mathrm{sd})$ increase of $0.16( \pm 0.34)$ (range: 0 to 1.6$)$ in MPOD was observed within 20 (range: 8 to 52) wks. However, it is important to point out that the magnitude of response is influenced by many factors, including the type of carotenoid used (i.e. L, Z, meso$Z$, independently or in combination), the concentration of carotenoid present in the supplement (dose), the duration of supplementation (time), individual characteristics (e.g. adiposity), and baseline MP levels.

However, the data suggest that supplementation with all three macular carotenoids results in the optimal response in terms of MP augmentation and changes in its spatial profile, although the data should be interpreted with full appreciation of the small number of trials involving supplemental meso-Z. Therefore, and given that the anti-oxidant capacity of MP is maximised in the presence of all three macular carotenoids, and where the objective is to augment MP and to putatively confer protection against AMD, current evidence suggests that supplementation with all three macular carotenoids is most likely to limit (photo)-oxidative retinal injury with a consequential reduction in risk of AMD development or progression.

Interestingly, a study by Bone and Landrum has shown that serum levels of $\mathrm{L}$ and $\mathrm{Z}$ rise and fall rapidly following commencement and discontinuation of supplementation with the macular carotenoids, respectively. In contrast, MP optical density increases more slowly from baseline following commencement of supplementation with the macular carotenoids, and returns to baseline levels more slowly following discontinuation of supplementation, reflecting a slow biological turnover or these carotenoids at the macula [145]. 


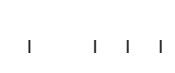

유

7

9

1

3

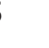

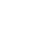




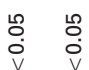

苗

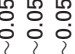

늉 늉 농 용

息

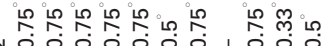

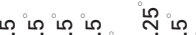

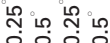

- ํํㅇ

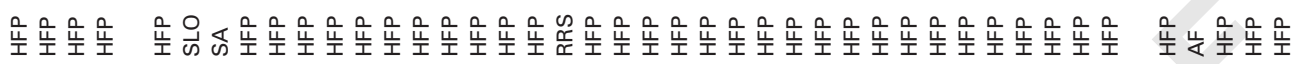

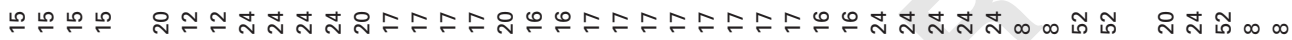

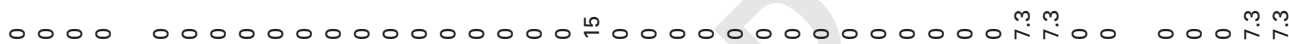

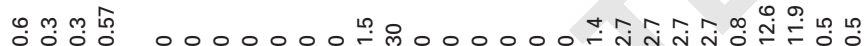
N $\stackrel{\infty}{0} \stackrel{\infty}{0}+-\quad 0-0 \stackrel{\infty}{0} \stackrel{\infty}{0} \stackrel{\infty}{0}$

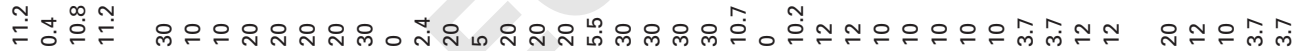

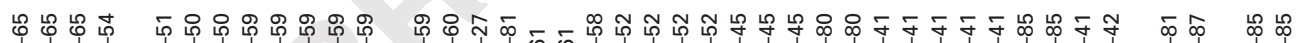

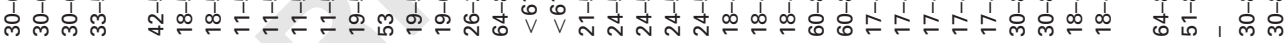

은 $n$ n

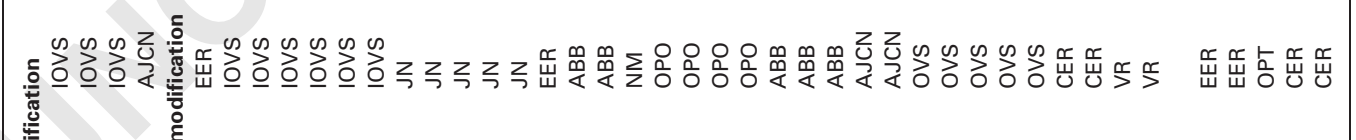

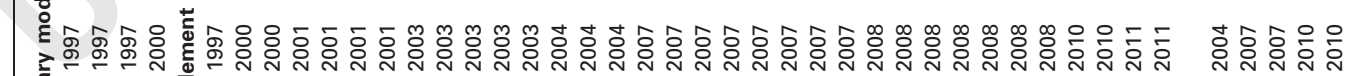




\subsection{A note on $\omega-3$ and AMD}

The role of $\boldsymbol{\omega}$-3 in AMD has generated considerable debate. The membranes of the photoreceptor outer segments have the highest concentration of PUFAs in the mammalian world [146], and their deficiency is associated with the onset of AMD [147]. These PUFAs are thought to protect against oxidative and inflammatory damage [148], processes which play a key role in the pathogenesis of AMD. On the other hand, such PUFAs are potentially the ideal substrate for the propagation of free radical damage associated with AMD [23]. There is a paucity of evidence for either of these hypotheses.

Two major systematic reviews have investigated $\boldsymbol{\omega}-3$ and its association with AMD. Hodge et al. appraised the evidence on the effects of $\boldsymbol{\omega}$-3 fatty acids in slowing down the progression of $\mathrm{AMD}$ and/or decreasing the rate of progression to advanced forms of the disease [149]. Only two studies were eligible for review, one of which (an RCT) indicated a beneficial effect of supplemental $\boldsymbol{\omega}$-3. However, confusion arising from the nutrient preparation with which patients were supplemented rendered it unclear as to whether $\boldsymbol{\omega}$-3 was indeed responsible for any observed benefit. A systematic review by Chong et al reviewed the evidence germane to dietary $\boldsymbol{\omega}-3$ and fish intake in the primary prevention of AMD [150], suggesting that the consumption of fish and foods rich in $\omega-3$ may be associated with a lower risk of AMD. This observational data does not necessarily indicate that any observed association represents a protective effect of $\boldsymbol{\omega}-3$ fatty acid intake, due to possible confounding (e.g meso-Z is also found in seafoods, or it may simply reflect a healthier lifestyle and diet in general amongst subjects with high consumption of fish).

Of note, AREDS 2 is also investigating the role of supplemental $\omega-3$ in AMD.

\section{Concluding remarks}

In summary, there is a biologically plausible rationale whereby MP protects against the development and progression of AMD. MP properties include its pre-receptoral filtration of damaging short-wavelength light and its ability to quench free radicals, processes which play a key role in the aetiopathogenesis of AMD. The undisputed risk factors for AMD (ageing, positive family history of disease and tobacoo use) are associated with a lack of MP prior to disease onset. There is level 1 evidence confirming that supplemental dietary anti-oxidants reduce the risk of vision loss in AMD, although evidence of this quality for supplementation with the macular carotenoids is still lacking. Dietary supplementation with the macular carotenoids (L, Z and/or meso-Z) results in augmentation of MP, and the best response in terms of augmentation, changes in spatial profile of the pigment and in terms of global fortification of the anti-oxidant defenses of the tissue to be protected, appears to be a supplement containing all three macular carotenoids. These trials, however, are limited by several factors, including small numbers of subjects and inadequate masking, such that definitive conclusions cannot yet be drawn.

To effectively investigate the putative protective role of carotenoid supplements in AMD, including a possible role in prevention of this condition, an RCT of considerable length (decades) would be required, and securing funding for such a study would be challenging indeed. As a consequence, it is important that we appraise the totality of currently available evidence in order to assist eyecare professionals to make well-informed decisions with respect to the prevention and/or delay of AMD onset and/or its progression. In this context, it would appear that supplementation with the macular carotenoids offers the best means of fortifying the anti-oxidant defenses of the macula, thus putatively reducing the risk of AMD and/or its progression.

The authors have declared no conflict of interest.

\section{References}

[1] Hirsch, J., Curcio, C. A., The spatial resolution capacity of human foveal retina. Vision Res. 1989, 29, 1095-1101.

[2] Attebo, K., Mitchell, P., Smith, W., Visual acuity and the causes of visual loss in Australia. The Blue Mountains Eye Study. Ophthalmology 1996, 103, 357-364.

[3] Klaver, C. C., Wolfs, R. C., Vingerling, J. R., Hofman, A., de Jong, P. T., Age-specific prevalence and causes of blindness and visual impairment in an older population: the Rotterdam Study. Arch. Ophthalmol. 1998, 116, 653-658.

[4] Resnikoff, S., Pascolini, D., Etya'ale, D., Kocur, I. et al., Global data on visual impairment in the year 2002. Bull. World Health Organ. 2004, 82, 844-851.

[5] Bressler, N. M., Age-related macular degeneration is the leading cause of blindness. J. Am. Med. Assoc. 2004, 291, 1900-1901.

[6] Owen, C. G., Fletcher, A. E., Donoghue, M., Rudnicka, A. R., How big is the burden of visual loss caused by age related macular degeneration in the United Kingdom? Br. J. Ophthalmol. 2003, 87, 312-317.

[7] Kelliher, C., Kenny, D., O'Brien, C., Trends in blind registration in the adult population of the Republic of Ireland 1996-2003. Br. J. Ophthalmol. 2006, 90, 367-371.

[8] Cahill, M. T., Banks, A. D., Stinnett, S. S., Toth, C. A., Vision-related quality of life in patients with bilateral severe age-related macular degeneration. Ophthalmology 2005, 112, 152-158.

[9] DeCarlo, D. K., Scilley, K., Wells, J., Owsley, C., Driving habits and health-related quality of life in patients with age-related maculopathy. Optom. Vis. Sci. 2003, 80, 207-213. 
[10] Lamoureux, E. L., Hassell, J. B., Keeffe, J. E., The determinants of participation in activities of daily living in people with impaired vision. Am. J. Ophthalmol. 2004, 137, 265-270.

[11] Hopley, C., Carter, R., Mitchell, P., Measurement of the economic impact of visual impairment from age-related macular degeneration in Australia. Clin. Exp. Ophthalmol. 2003, 31, 522-529.

[12] Rein, D. B., Zhang, P., Wirth, K. E., Lee, P. P. et al., The economic burden of major adult visual disorders in the United States. Arch. Ophthalmol. 2006, 124, 1754-1760.

[13] Schork, N. J., Genetics of complex disease: approaches, problems, and solutions. Am. J. Respir. Crit Care Med. 1997, 156, S103-S109.

[14] Cai, J., Nelson, K. C., Wu, M., Sternberg, P., Jr., Jones, D. P., Oxidative damage and protection of the RPE. Prog. Retin. Eye Res. 2000, 19, 205-221.

[15] Rosenfeld, P. J., Brown, D. M., Heier, J. S., Boyer, D. S. et al., Ranibizumab for neovascular age-related macular degeneration. N. Engl. J. Med. 2006, 355, 1419-1431.

[16] Brown, D. M., Michels, M., Kaiser, P. K., Heier, J. S. et al., Ranibizumab versus verteporfin photodynamic therapy for neovascular age-related macular degeneration: two-year results of the ANCHOR study. Ophthalmology 2009, 116, 57-65.

[17] Bressler, N. M., Chang, T. S., Suner, I. J., Fine, J. T. et al., Vision-related function after ranibizumab treatment by better- or worse-seeing eye: clinical trial results from MARINA and ANCHOR. Ophthalmology 2010, 117, 747-756.

[18] Sommerburg, O., Keunen, J. E., Bird, A. C., van Kuijk, F. J., Fruits and vegetables that are sources for lutein and zeaxanthin: the macular pigment in human eyes. $\mathrm{Br}$. J. Ophthalmol. 1998, 82, 907-910.

[19] Maoka, T., Arai, A., Shimizu, M., Matsuno, T., The first isolation of enantiomeric and meso-zeaxanthin in nature. Comp. Biochem. Physiol B. 1986, 83, 121-124.

[20] Johnson, E. J., Neuringer, M., Russell, R. M., Schalch, W., Snodderly, D. M., Nutritional manipulation of primate retinas, III: Effects of lutein or zeaxanthin supplementation on adipose tissue and retina of xanthophyll-free monkeys. Invest. Ophthalmol. Vis. Sci. 2005, 46, 692-702.

[21] Bone, R. A., Landrum, J. T., Hime, G. W., Cains, A., Zamor, J., Stereochemistry of the human macular carotenoids. Invest. Ophthalmol. Vis. Sci. 1993, 34, 2033-2040.

[22] Tomany, S. C., Cruickshanks, K. J., Klein, R., Klein, B. E., Knudtson, M. D., Sunlight and the 10-year incidence of age-related maculopathy: the Beaver Dam Eye Study. Arch. Ophthalmol. 2004, 122, 750-757.

[23] Beatty, S., Koh, H., Phil, M., Henson, D., Boulton, M., The role of oxidative stress in the pathogenesis of age-related macular degeneration. Surv. Ophthalmol. 2000, 45, 115-134.

[24] Harman, D., Aging: A theory based on free radical and radiation chemistry. J. Gerontol. 1956, 11, 298-300.

[25] Harman, D., The biologic clock: the mitochondria? J. Am. Geriatr. Soc. 1972, 20, 145-147.
[26] Halliwell, B., Antioxidants and human disease: a general introduction. Nutr. Rev. 1997, 55, S44-S49.

[27] Sies, H., Oxidative stress: from basic research to clinical application. Am. J. Med. 1991, 91, 31S-38S.

[28] Machlin, L. J., Bendich, A., Free radical tissue damage: protective role of antioxidant nutrients. FASEB J. 1987, 1, 441-445.

[29] Borish, E. T., Pryor, W. A., Venugopal, S., Deutsch, W. A., DNA synthesis is blocked by cigarette tar-induced DNA single-strand breaks. Carcinogenesis 1987, 8, 1517-1520.

[30] McCord, J. M., The evolution of free radicals and oxidative stress. Am. J. Med. 2000, 108, 652-659.

[31] Bok, D., The retinal pigment epithelium: a versatile partner in vision. J. Cell Sci. Suppl. 1993, 17, 189-195.

[32] Steinberg, R. H., Interactions between the retinal pigment epithelium and the neural retina. Doc. Ophthalmol. 1985, $60,327-346$.

[33] Curcio, C. A., Medeiros, N. E., Millican, C. L., Photoreceptor loss in age-related macular degeneration. Invest. Ophthalmol. Vis. Sci. 1996, 37, 1236-1249.

[34] Katz, M. L., Robison, W. G., Jr., What is lipofuscin? Defining characteristics and differentiation from other autofluorescent lysosomal storage bodies. Arch. Gerontol. Geriatr. 2002, 34, 169-184.

[35] Kennedy, C. J., Rakoczy, P. E., Constable, I. J., Lipofuscin of the retinal pigment epithelium: a review. Eye (London) 1995, 9, 763-771.

[36] Rozanowska, M., Jarvis-Evans, J., Korytowski, W., Boulton, M. E. et al., Blue light-induced reactivity of retinal age pigment. In vitro generation of oxygen-reactive species. J. Biol. Chem. 1995, 270, 18825-18830.

[37] Sundelin, S., Wihlmark, U., Nilsson, S. E., Brunk, U. T., Lipofuscin accumulation in cultured retinal pigment epithelial cells reduces their phagocytic capacity. Curr. Eye Res. 1998, 17, 851-857.

[38] Schalch, W., Carotenoids in the retina - A review of their possible role in preventing or limiting damage caused by light and oxygen. EXS 1992, 62, 280-298.

[39] Ham, W. T., Jr., Mueller, H. A., Sliney, D. H., Retinal sensitivity to damage from short wavelength light. Nature 1976, 260, 153-155.

[40] Pitts, D. G., A comparative study of the effects of ultraviolet radiation on the eye. Am. J. Optom. Arch. Am. Acad. Optom. 1970, 47, 535-546.

[41] Algvere, P. V., Marshall, J., Seregard, S., Age-related maculopathy and the impact of blue light hazard. Acta Ophthalmol. Scand. 2006, 84, 4-15.

[42] Noell, W. K., Walker, V. S., Kang, B. S., Berman, S., Retinal damage by light in rats. Invest. Ophthalmol. 1966, 5, 450-473.

[43] Wu, J., Seregard, S., Algvere, P. V., Photochemical damage of the retina. Surv. Ophthalmol. 2006, 51, 461-481.

[44] Ruffolo, J. J., Jr., Ham, W. T., Jr., Mueller, H. A., Millen, J. E., Photochemical lesions in the primate retina under conditions of elevated blood oxygen. Invest. Ophthalmol. Vis. Sci. 1984, 25, 893-898. 
[45] Boulton, M., Dontsov, A., Jarvis-Evans, J., Ostrovsky, M., Svistunenko, D., Lipofuscin is a photoinducible free radical generator. J. Photochem. Photobiol. B 1993, 19, 201-204.

[46] Shaban, H., Borras, C., Vina, J., Richter, C., Phosphatidylglycerol potently protects human retinal pigment epithelial cells against apoptosis induced by $A 2 E$, a compound suspected to cause age-related macula degeneration. Exp. Eye Res. 2002, 75, 99-108.

[47] Sparrow, J. R., Vollmer-Snarr, H. R., Zhou, J., Jang, Y. P. et al., A2E-epoxides damage DNA in retinal pigment epithelial cells. Vitamin $E$ and other antioxidants inhibit A2Eepoxide formation. J. Biol. Chem. 2003, 278, 18207-18213.

[48] Taylor, H. R., Munoz, B., West, S., Bressler, N. M. et al., Visible light and risk of age-related macular degeneration. Trans. Am. Ophthalmol. Soc. 1990, 88, 163-173; discussion 173-178, 163-173.

[49] Wiegand, R. D., Giusto, N. M., Rapp, L. M., Anderson, R. E., Evidence for rod outer segment lipid peroxidation following constant illumination of the rat retina. Invest. Ophthalmol. Vis. Sci. 1983, 24, 1433-1435.

[50] Ham, W. T., Jr., Ruffolo, J. J., Jr., Mueller, H. A., Clarke, A. M., Moon, M. E., Histologic analysis of photochemical lesions produced in rhesus retina by short-wave-length light. Invest. Ophthalmol. Vis. Sci. 1978, 17, 1029-1035.

[51] Lam, S., Tso, M. O., Gurne, D. H., Amelioration of retinal photic injury in albino rats by dimethylthiourea. Arch. Ophthalmol. 1990, 108, 1751-1757.

[52] Suzuki, M., Kamei, M., Itabe, H., Yoneda, K. et al., Oxidized phospholipids in the macula increase with age and in eyes with age-related macular degeneration. Mol. Vis. 2007, 13, 772-778, 772-778.

[53] Lu, L., Hackett, S. F., Mincey, A., Lai, H., Campochiaro, P. A., Effects of different types of oxidative stress in RPE cells. J. Cell Physiol. 2006, 206, 119-125.

[54] Seddon, J. M., Gensler, G., Milton, R. C., Klein, M. L., Rifai, $\mathrm{N}$., Association between $\mathrm{C}$-reactive protein and age-related macular degeneration. J. Am. Med. Assoc. 2004, 291, 704-710.

[55] Donoso, L. A., Kim, D., Frost, A., Callahan, A., Hageman, G., The role of inflammation in the pathogenesis of agerelated macular degeneration. Surv. Ophthalmol. 2006, 51, 137-152.

[56] Ferrero-Miliani, L., Nielsen, O. H., Andersen, P. S., Girardin, S. E., Chronic inflammation: importance of NOD2 and NALP3 in interleukin-1beta generation. Clin. Exp. Immunol. 2007, 147, 227-235.

[57] Johnson, L. V., Leitner, W. P., Staples, M. K., Anderson, D. H., Complement activation and inflammatory processes in Drusen formation and age related macular degeneration. Exp. Eye Res. 2001, 73, 887-896.

[58] Hageman, G. S., Luthert, P. J., Victor Chong, N. H., Johnson, L. V. et al., An integrated hypothesis that considers drusen as biomarkers of immune-mediated processes at the RPE-Bruch's membrane interface in aging and agerelated macular degeneration. Prog. Retin. Eye Res. 2001, $20,705-732$.
[59] Anderson, D. H., Mullins, R. F., Hageman, G. S., Johnson, L. V., A role for local inflammation in the formation of drusen in the aging eye. Am. J. Ophthalmol. 2002, 134, 411-431.

[60] Li, C. M., Clark, M. E., Chimento, M. F., Curcio, C. A., Apolipoprotein localization in isolated drusen and retinal apolipoprotein gene expression. Invest. Ophthalmol. Vis. Sci. 2006, 47, 3119-3128.

[61] Umeda, S., Suzuki, M. T., Okamoto, H., Ono, F. et al., Molecular composition of drusen and possible involvement of anti-retinal autoimmunity in two different forms of macular degeneration in cynomolgus monkey (Macaca fascicularis). FASEB J. 2005, 19, 1683-1685.

[62] Dentchev, T., Milam, A. H., Lee, V. M., Trojanowski, J. Q., Dunaief, J. L., Amyloid-beta is found in drusen from some age-related macular degeneration retinas, but not in drusen from normal retinas. Mol. Vis. 2003, 9, 184-190, 184-190.

[63] Francis, P. J., Schultz, D. W., Hamon, S., Ott, J. et al., Haplotypes in the complement factor $\mathrm{H}(\mathrm{CFH})$ gene: associations with drusen and advanced age-related macular degeneration. PLoS One 2007, 2, e1197.

[64] Doney, A. S., Leese, G. P., Olson, J., Morris, A. D., Palmer, C. N., The $\mathrm{Y} 402 \mathrm{H}$ variant of complement factor $\mathrm{H}$ is associated with age-related macular degeneration but not with diabetic retinal disease in the Go-DARTS study. Diabet. Med. 2009, 26, 460-465.

[65] Hollyfield, J. G., Bonilha, V. L., Rayborn, M. E., Yang, X. et al., Oxidative damage-induced inflammation initiates age-related macular degeneration. Nat. Med. 2008, 14, 194-198.

[66] Klein, R., Cruickshanks, K. J., Nash, S. D., Krantz, E. M. et al., The prevalence of age-related macular degeneration and associated risk factors. Arch. Ophthalmol. 2010, 128, 750-758.

[67] Smith, W., Assink, J., Klein, R., Mitchell, P. et al., Risk factors for age-related macular degeneration: pooled findings from three continents. Ophthalmology 2001, 108, 697-704.

[68] Silvestri, G., Johnston, P. B., Hughes, A. E., Is genetic predisposition an important risk factor in age-related macular degeneration? Eye (London) 1994, 8, 564-568.

[69] Klein, R., Klein, B. E., Moss, S. E., Relation of smoking to the incidence of age-related maculopathy. The Beaver Dam Eye Study. Am. J. Epidemiol. 1998, 147, 103-110.

[70] Seddon, J. M., Francis, P. J., George, S., Schultz, D. W. et al., Association of CFH Y402H and LOC387715 A69S with progression of age-related macular degeneration. J. Am. Med. Assoc. 2007, 297, 1793-1800.

[71] Mares, J. A., Voland, R. P., Sondel, S. A., Millen, A. E. et al., Healthy lifestyles related to subsequent prevalence of agerelated macular degeneration. Arch. Ophthalmol. 2010.

[72] SanGiovanni, J. P., Chew, E. Y., Clemons, T. E., Ferris, F. L., III et al., The relationship of dietary carotenoid and vitamin $A, E$, and $C$ intake with age-related macular degeneration in a case-control study: AREDS Report No. 22. Arch. Ophthalmol. 2007, 125, 1225-1232. 
[73] Nolan, J. M., Stack, J., O', D. O., Loane, E., Beatty, S., Risk factors for age-related maculopathy are associated with a relative lack of macular pigment. Exp. Eye Res. 2007, 84, 61-74.

[74] Kirby, M. L., Beatty, S., Loane, E., Akkali, M. C. et al., A central dip in the macular pigment spatial profile is associated with age and smoking. Invest. Ophthalmol. Vis. Sci. 2010, 51, 6722-6728.

[75] Buzzi, F., Nuove sperienze fatte sulli occhio umano 1792.

[76] Soemmering, S., De foramina centrali limbo luteo cincto retinae humanae. Comment Soc. Reg. Sci. Goetting 1799, 13.

[77] Home, E., An account of the orifice in the retina of the human eye, discovered by Professor Soemmering: To which are added proofs of this appearance being extended to the eyes of other animals. Philos. Trans. R. Soc. London $1798,2,332$.

[78] Nussbaum, J. J., Pruett, R. C., Delori, F. C., Historic perspectives. Macular yellow pigment. The first 200 years. Retina 1981, 1, 296-310.

[79] Walls, G. L. J. H. D., The intra-ocular colour-filters of vertebrates. Br. J. Ophthalmol. 1933, 17, 641-675.

[80] Schultze, M., Ueber den gelben Fleck der Retina, seinen Einfluss auf normales Sehen und auf Farbenblindheit 1866.

[81] Chevalleraeu, A., De la colouration jaune de la macula. Ann. Oculist 1907, 241.

[82] Henning, H., Optische Versuche an Vogeln und Schildkroten uber die Bedeutung der roten Oelkugeln im Auge. Arch. Gesphysiol 1920, 91-123.

[83] Erhard, H., Messende Untersuchungen ueber den Farbensinn der Vogel. Zool. Jahrb. (Zool. Physiol.) 1924, 489-552.

[84] Wald, G., Human vision and the spectrum. Science 1945, 101, 653-658.

[85] Bone, R. A., Landrum, J. T., Tarsis, S. L., Preliminary identification of the human macular pigment. Vis. Res. 1985, 25, 1531-1535.

[86] Handelman, G. J., Dratz, E. A., Reay, C. C., van Kuijk, J. G., Carotenoids in the human macula and whole retina. Invest. Ophthalmol. Vis. Sci. 1988, 29, 850-855.

[87] Landrum, J. T., Bone, R. A., Moore, L. L., Gomez, C. M., Analysis of zeaxanthin distribution within individual human retinas. Methods Enzymol. 1999, 299, 457-467.

[88] Neuringer, M., Sandstrom, M. M., Johnson, E. J., Snodderly, D. M., Nutritional manipulation of primate retinas, I: effects of lutein or zeaxanthin supplements on serum and macular pigment in xanthophyll-free rhesus monkeys. Invest. Ophthalmol. Vis. Sci. 2004, 45, 3234-3243.

[89] Bone, R. A., Landrum, J. T., Friedes, L. M., Gomez, C. M. et al., Distribution of lutein and zeaxanthin stereoisomers in the human retina. Exp. Eye Res. 1997, 64, 211-218.

[90] Whitehead, A. J., Mares, J. A., Danis, R. P., Macular pigment: A review of current knowledge. Arch. Ophthalmol. 2006, 124, 1038-1045.

[91] Sujak, A., Gabrielska, J., Grudzinski, W., Borc, R. et al., Lutein and zeaxanthin as protectors of lipid membranes against oxidative damage: the structural aspects. Arch. Biochem. Biophys. 1999, 371, 301-307.

[92] Landrum, J. T., Bone, R. A., Lutein, zeaxanthin, and the macular pigment. Arch. Biochem. Biophys. 2001, 385, 28-40.

[93] Billsten, H. H., Bhosale, P., Yemelyanov, A., Bernstein, P. S., Polivka, T., Photophysical properties of xanthophylls in carotenoproteins from human retinas. Photochem. Photobiol. 2003, 78, 138-145.

[94] Fletcher, A. E., Bentham, G. C., Agnew, M., Young, I. S. et al., Sunlight exposure, antioxidants, and age-related macular degeneration. Arch. Ophthalmol. 2008, 126, 1396-1403.

[95] Barker, F. M., Snodderly, D. M., Johnson, E. J., Schalch, W. et al., Nutritional manipulation of primate retinas. V: Effects of lutein, zeaxanthin and $n-3$ fatty acids on retinal sensitivity to blue light damage. Invest. Ophthalmol. Vis. Sci. 2011.

[96] Sundelin, S. P., Nilsson, S. E., Lipofuscin-formation in retinal pigment epithelial cells is reduced by antioxidants. Free Radic. Biol. Med. 2001, 31, 217-225.

[97] Trevithick-Sutton, C. C., Foote, C. S., Collins, M., Trevithick, J. R., The retinal carotenoids zeaxanthin and lutein scavenge superoxide and hydroxyl radicals: a chemiluminescence and ESR study. Mol. Vis. 2006, 12, 1127-1135, $1127-1135$.

[98] Kirschfeld, K., Carotenoid pigments: Their possible role in protecting against photooxidation in eyes and photoreceptor cells. Proc. R. Soc. London B Biol. Sci. 1982, 216, 71-85.

[99] Khachik, F., Bernstein, P. S., Garland, D. L., Identification of lutein and zeaxanthin oxidation products in human and monkey retinas. Invest. Ophthalmol. Vis. Sci. 1997, 38, 1802-1811.

[100] Jorgensen, K., Skibsted, L. H., Carotenoid scavenging of radicals. Effect of carotenoid structure and oxygen partial pressure on antioxidative activity. Z. Lebensm. Unters. Forsch. 1993, 196, 423-429.

[101] Snodderly, D. M., Auran, J. D., Delori, F. C., The macular pigment. II. Spatial distribution in primate retinas. Invest. Ophthalmol. Vis. Sci. 1984, 25, 674-685.

[102] Trieschmann, M., van Kuijk, F. J., Alexander, R., Hermans, P. et al., Macular pigment in the human retina: histological evaluation of localization and distribution. Eye (London) 2008, 22, 132-137.

[103] Beatty, S., Boulton, M., Henson, D., Koh, H. H., Murray, I. J., Macular pigment and age related macular degeneration. Br. J. Ophthalmol. 1999, 83, 867-877.

[104] Wrona, M., Rozanowska, M., Sarna, T., Zeaxanthin in combination with ascorbic acid or alpha-tocopherol protects ARPE-19 cells against photosensitized peroxidation of lipids. Free Radic. Biol. Med. 2004, 36, 1094-1101.

[105] Siems, W. G., Sommerburg, O., van Kuijk, F. J., Lycopene and beta-carotene decompose more rapidly than lutein and zeaxanthin upon exposure to various pro-oxidants in vitro. Biofactors 1999, 10, 105-113. 
[106] Cantrell, A., McGarvey, D. J., Truscott, T. G., Rancan, F., Bohm, F., Singlet oxygen quenching by dietary carotenoids in a model membrane environment. Arch. Biochem. Biophys. 2003, 412, 47-54.

[107] Bhosale, P., Bernstein, P. S., Synergistic effects of zeaxanthin and its binding protein in the prevention of lipid membrane oxidation. Biochim. Biophys. Acta. 2005, 1740, $116-121$.

[108] Thomson, L. R., Toyoda, Y., Langner, A., Delori, F. C. et al., Elevated retinal zeaxanthin and prevention of lightinduced photoreceptor cell death in quail. Invest. Ophthalmol Vis. Sci. 2002, 43, 3538-3549.

[109] Chucair, A. J., Rotstein, N. P., SanGiovanni, J. P., During, A. et al., Lutein and zeaxanthin protect photoreceptors from apoptosis induced by oxidative stress: relation with docosahexaenoic acid. Invest. Ophthalmol Vis. Sci. 2007, 48, 5168-5177.

[110] Li, B., Ahmed, F., Bernstein, P. S., Studies on the singlet oxygen scavenging mechanism of human macular pigment. Arch. Biochem. Biophys. 2010, 504, 56-60.

[111] Nebeling, L. C., Forman, M. R., Graubard, B. I., Snyder, R. A., The impact of lifestyle characteristics on carotenoid intake in the United States: the 1987 National Health Interview Survey. Am. J. Public Health. 1997, 87, 268-271.

[112] Perry, A., Rasmussen, H., Johnson, E., Xanthophyll (lutein, zeaxanthin) content in fruits, vegetables and corn and egg products. J. Food Comp. Anal. 2009, 22, 9-15.

[113] Chung, H. Y., Rasmussen, H. M., Johnson, E. J., Lutein bioavailability is higher from lutein-enriched eggs than from supplements and spinach in men. J. Nutr. 2004, 134, 1887-1893.

[114] Thurnham, D. I., Macular zeaxanthins and lutein - a review of dietary sources and bioavailability and some relationships with macular pigment optical density and age-related macular disease. Nutr. Res. Rev. 2007, 20, 163-179.

[115] Connolly, E. E., Beatty, S., Thurnham, D. I., Loughman, J. et al., Augmentation of macular pigment following supplementation with all three macular carotenoids: an exploratory study. Curr. Eye Res. 2010, 35, 335-351.

[116] Harbour, R., Miller, J., A new system for grading recommendations in evidence based guidelines. BMJ 2001, 323, 334-336.

[117] Sackett, D. L., The Cochrane Collaboration. ACP J. Club. 1994, 120, A11., A11.

[118] Black, N., Why we need observational studies to evaluate the effectiveness of health care. BMJ 1996, 312, 1215-1218.

[119] Stephenson, J., Imrie, J., Why do we need randomised controlled trials to assess behavioural interventions? BMJ $1998,316,611-613$.

[120] Hennekens, C. H., Buring, J. E., Observational evidence. Ann NY Acad. Sci. 1993, 703, 18-24; discussion 24, 18-24.

[121] Rychetnik, L., Frommer, M., Hawe, P., Shiell, A., Criteria for evaluating evidence on public health interventions. J. Epidemiol. Community Health. 2002, 56, 119-127.

[122] Richer, S., ARMD - pilot (case series) environmental intervention data. J. Am. Optom. Assoc. 1999, 70, 24-36.
[123] Olmedilla, B., Granado, F., Blanco, I., Vaquero, M., Cajigal, C., Lutein in patients with cataracts and age-related macular degeneration: a long-term supplementation study. J. Sci. Food Agric. 2001, 81, 904-909.

[124] Bartlett, H. E., Eperjesi, F., Effect of lutein and antioxidant dietary supplementation on contrast sensitivity in agerelated macular disease: a randomized controlled trial. Eur. J. Clin. Nutr. 2007, 61, 1121-1127.

[125] Richer, S., Stiles, W., Statkute, L., Pulido, J. et al., Doublemasked, placebo-controlled, randomized trial of lutein and antioxidant supplementation in the intervention of atrophic age-related macular degeneration: the Veterans LAST study (Lutein Antioxidant Supplementation Trial). Optometry 2004, 75, 216-230.

[126] Chakravarthy, U., Beatty, S., Stevenson, M., The CARMA study group, 2009.

[127] Neelam, K., Hogg, R. E., Stevenson, M. R., Johnston, E. et al., Carotenoids and co-antioxidants in age-related maculopathy: design and methods. Ophthal. Epidemiol. 2008, 15, 389-401.

[128] Weigert, G., Kaya, S., Pemp, B., Lasta, M. et al., 2011.

[129] Jentsch, S., Schweitzer, D., Hammer, M., Lang, G. E., J Dawczynski, 2011.

[130] Kenny, R., Whelan, B. J., Cronin, H., Kamiya, Y. et al., 2010.

[131] Nolan, J. M., Kenny, R., O'Regan, C., Cronin, H. et al., Macular pigment optical density in an ageing Irish population: The Irish Longitudinal Study on Ageing. Ophthal. Res. 2010, 44, 131-139.

[132] Seddon, J. M., Ajani, U. A., Sperduto, R. D., Hiller, R. et al., Dietary carotenoids, vitamins $A, C$, and $E$, and advanced age-related macular degeneration. Eye Disease CaseControl Study Group. J. Am. Med. Assoc. 1994, 272, 1413-1420.

[133] VandenLangenberg, G. M., Mares-Perlman, J. A., Klein, R., Klein, B. E. et al., Associations between antioxidant and zinc intake and the 5-year incidence of early age-related maculopathy in the Beaver Dam Eye Study. Am. J. Epidemiol. 1998, 148, 204-214.

[134] Mares-Perlman, J. A., Fisher, A. I., Klein, R., Palta, M. et al., Lutein and zeaxanthin in the diet and serum and their relation to age-related maculopathy in the third national health and nutrition examination survey. Am. J. Epidemiol. 2001, 153, 424-432.

[135] Flood, V., Smith, W., Wang, J. J., Manzi, F. et al., Dietary antioxidant intake and incidence of early age-related maculopathy: the Blue Mountains Eye Study. Ophthalmology 2002, 109, 2272-2278.

[136] Moeller, S. M., Parekh, N., Tinker, L., Ritenbaugh, C. et al., Associations between intermediate age-related macular degeneration and lutein and zeaxanthin in the Carotenoids in Age-related Eye Disease Study (CAREDS): ancillary study of the Women's Health Initiative. Arch. Ophthalmol. 2006, 124, 1151-1162.

[137] Snellen, E. L., Verbeek, A. L., Van Den Hoogen, G. W., Cruysberg, J. R., Hoyng, C. B., Neovascular age-related macular degeneration and its relationship to antioxidant intake. Acta Ophthalmol. Scand. 2002, 80, 368-371. 
[138] Tan, J. S., Wang, J. J., Flood, V., Rochtchina, E. et al., Dietary antioxidants and the long-term incidence of agerelated macular degeneration: the Blue Mountains Eye Study. Ophthalmology 2008, 115, 334-341.

[139] Antioxidant status and neovascular age-related macular degeneration. Eye Disease Case-Control Study Group. Arch. Ophthalmol. 1993, 111, 104-109.

[140] Mares-Perlman, J. A., Brady, W. E., Klein, R., Klein, B. E. et al., Serum antioxidants and age-related macular degeneration in a population-based case-control study. Arch. Ophthalmol. 1995, 113, 1518-1523.

[141] Simonelli, F., Zarrilli, F., Mazzeo, S., Verde, V. et al., Serum oxidative and antioxidant parameters in a group of Italian patients with age-related maculopathy. Clin. Chim. Acta. 2002, 320, 111-115.

[142] Gale, C. R., Hall, N. F., Phillips, D. I., Martyn, C. N., Lutein and zeaxanthin status and risk of age-related macular degeneration. Invest. Ophthalmol. Vis. Sci. 2003, 44, 2461-2465.

[143] Cardinault, N., Abalain, J. H., Sairafi, B., Coudray, C. et al., Lycopene but not lutein nor zeaxanthin decreases in serum and lipoproteins in age-related macular degeneration patients. Clin. Chim. Acta 2005, 357, 34-42.

[144] Delcourt, C., Carriere, I., Delage, M., Barberger-Gateau, P., Schalch, W., Plasma lutein and zeaxanthin and other carotenoids as modifiable risk factors for age-related maculopathy and cataract: The POLA Study. Invest. Ophthalmol. Vis. Sci. 2006, 47, 2329-2335.

[145] Landrum, J. T., Bone, R. A., Joa, H., Kilburn, M. D. et al., A one year study of the macular pigment: the effect of 140 days of a lutein supplement. Exp. Eye Res. 1997, 65, 57-62.

[146] Stone, W. L., Farnsworth, C. C., Dratz, E. A., A reinvestigation of the fatty acid content of bovine, rat and frog retinal rod outer segments. Exp. Eye Res. 1979, 28, 387-397.

[147] Bazan, N. G., The metabolism of omega-3 polyunsaturated fatty acids in the eye: the possible role of docosahexaenoic acid and docosanoids in retinal physiology and ocular pathology. Prog. Clin. Biol. Res. 1989, 312, 95-112.

[148] SanGiovanni, J. P., Chew, E. Y., The role of omega-3 longchain polyunsaturated fatty acids in health and disease of the retina. Prog. Retin. Eye Res. 2005, 24, 87-138.

[149] Hodge, W. G., Barnes, D., Schachter, H. M., Pan, Y. I. et al., Evidence for the effect of omega-3 fatty acids on progression of age-related macular degeneration: A systematic review. Retina 2007, 27, 216-221.

[150] Chong, E. W., Kreis, A. J., Wong, T. Y., Simpson, J. A., Guymer, R. H., Dietary omega-3 fatty acid and fish intake in the primary prevention of age-related macular degeneration: a systematic review and meta-analysis. Arch. Ophthalmol. 2008, 126, 826-833. 


\section{QUERY FORM}

\section{Wiley-VCH Germany}

JOURNAL TITLE: MNFR

$17 / 10 / 2011$

ARTICLE NO:

201100219

Quries and / or remarks

\begin{tabular}{|c|l|c|}
\hline Query No. & \multicolumn{1}{|c|}{ Details Required } & Author's Response \\
\hline AQ1 & Please provide title for corresponding author. & \\
\hline AQ2 & Please check the identification of section headings. & \\
\hline AQ3 & Please update Refs. [71, 95, 128, 129, 130]. & \\
\hline AQ4 & Please provide author names for Ref. [139]. & \\
\hline
\end{tabular}

